\section{Star quality}

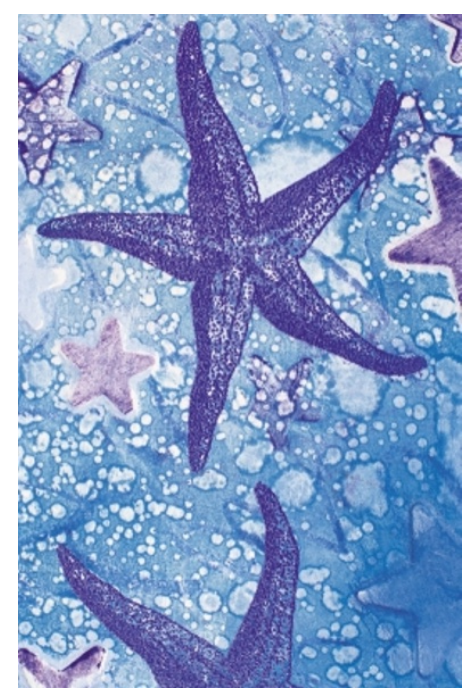

It is now well established that certain regions of the brain, such as the subventricular zone and the hippocampus, continue to generate neurons throughout life, whereas others lose this ability as the brain matures. A new study by Song et al., reported in Nature, indicates that a star-shaped glial cell — the astrocyte - might hold the key to this variation.

Even parts of the brain that do not normally generate neurons often contain stem cells, and these cells can be made to differentiate into neurons if they are transplanted into neurogenic regions. So, the local tissue environment must be important in determining whether or not a region is neurogenic. To find out which components of the brain tissue are responsible for creating a neurogenic environment, Song et al. extracted stem cells from the adult rat hippocampus and tried to culture them on a feeder layer of either hippocampal astrocytes or neurons.

The cells that were grown with astrocytes gave rise to a high proportion of neurons, whereas those grown with neurons generated large numbers of oligodendrocytes. The effects of the astrocytes were twofold: they increased the rate of proliferation of the stem cells and they biased their specification towards a neuronal fate. Adult hippocampal astrocytes were less effective in promoting neurogenesis than those from the neonatal brain, perhaps reflecting the general age-related decline in the brain's ability to generate new neurons. The origin of the astrocytes was also important; for example, astrocytes from the adult spinal cord, which is non-neurogenic, could not induce hippocampal stem cells to differentiate into neurons.

For a long time, astrocytes were considered to have a rather passive supporting role in the central nervous system, but it seems that they are much more interesting than we previously imagined. Last year, it was shown that they participate in the formation and maintenance of synapses, and Song et al. now show that hippocampal astrocytes can promote neurogenesis from adult neural stem cells. In the developing brain, on the other hand, the onset of neurogenesis precedes gliogenesis, so it is likely that embryonic neural stem cells differentiate in response to different signals than their adult counterparts.

Of course, it remains to be shown that hippocampal astrocytes can stimulate neurogenesis in vivo, and it will also be interesting to find out whether this is a general property of astrocytes in neurogenic regions of the brain. If this proves to be the case, it raises the possibility that astrocytes from neurogenic regions could be used to stimulate the production of neurons in non-neurogenic regions, simply by mobilizing stem cells that are already present. This could have significant implications for brain repair, possibly leading to the development of new strategies that emphasize the importance of providing the right environment to promote neuronal differentiation.

Heather Wood

\section{(2) References and links} ORIGINAL RESEARCH PAPER Song, H. et al. Astroglia induce neurogenesis from adult neural stem cells. Nature 417, 39-44 (2002) FURTHER READING Svendsen, C. N. The amazing astrocyte. Nature 417, 29-32 (2002) Rossi, F. \& Cattaneo, E. Neural stem cell therapy for neurological diseases: dreams and reality. Nature Rev. Neurosci. 3, 401-409 (2002) WEB SITES

Encyclopedia of Life Sciences: http://www.els.net/ astrocytes and brain signalling
BEHAVIOURAL NEUROSCIENCE

\section{Dipsomaniac mice?}

Worried about that deadline you have to meet? Fancy a beer to help you cope with stress? This reaction might seem exclusive to humans but, as a recent paper in Science shows, something similar is observed in mice that lack a receptor for corticotropinreleasing hormone (CRH).

Alcoholism depends on both environmental and genetic factors. It is well known that stress can have a profound influence on alcohol intake, and some studies have implicated the CRH system in stress-induced alcohol drinking. Sillaber et al. followed this lead and measured voluntary alcohol intake in mice lacking the CRH1 receptor, testing whether stress had any effect on drinking behaviour. They found that, under basal conditions, the knockout mice did not drink more alcohol than their wild-type littermates. However, after repeated stress, the knockout mice started to drink more alcohol on a regular basis. Intriguingly, this behavioural change was not observed immediately after the stressful events; it developed gradually over several weeks and lasted for at least six months, even when the animals were not confronted with any further stressful experience.

As glutamate-mediated neurotransmission has also been implicated in stressinduced alcohol drinking, Sillaber et al. looked for changes in this system that might help to explain the behavioural response of the knockout mice. They found that the NMDA ( $N$-methyl-D-aspartate) receptor subunit NR2B was upregulated in the hippocampus and nucleus accumbens of these animals.

The results of Sillaber et al. point to the CRH1 and NR2B receptors as possible risk factors for alcoholism, but they actually raise more questions than they answer. Why does stress elicit such a delayed effect on alcohol intake, instead of an immediate behavioural reaction? Given

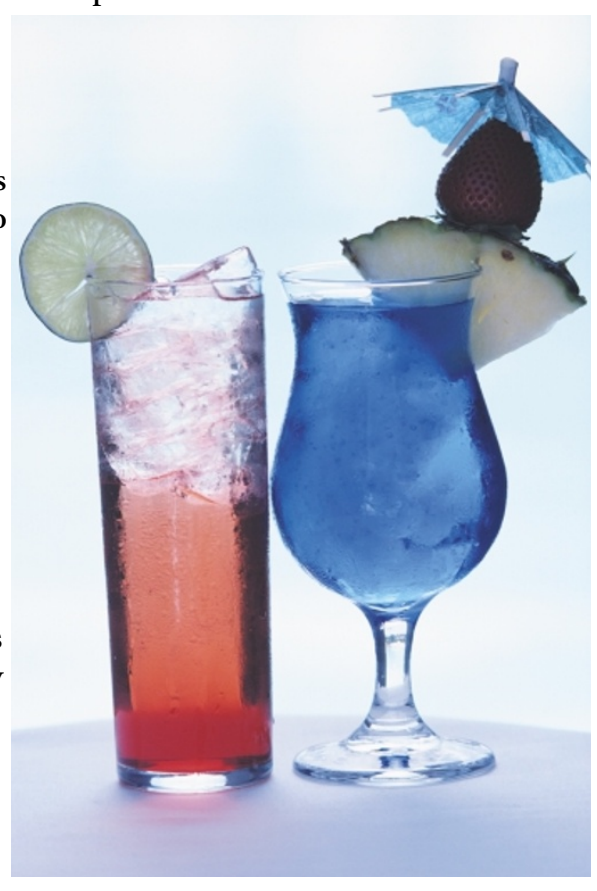
that the stress response of the knockout animals is reduced, why does the absence of CRH1 increase their susceptibility to stressinduced alcohol intake, instead of decreasing it? More importantly, do these knockout animals constitute an ideal model of alcoholism? I'll have another drink before joining the authors to ponder these questions.

(2) References and links

Juan Carlos López

ORIGINAL RESEARCH PAPER Sillaber, l. et al. Enhanced and delayed stress-induced

alcohol drinking in mice lacking functional CRH1 receptors. Science 296, 931-933 (2002) FURTHER READING Weiss, F. \& Porrino, L. J. Behavioural neurobiology of alcohol addiction: recent advances and challenges. J. Neurosci. 22, 3332-3337 (2002) WEB SITES

Encyclopedia of Life Sciences: http://www.els.net/ alcoholism 